\title{
A língua brasileira e os sentidos de nacionalidade e mestiçagem no Império do Brasil *
}

\section{Ivana Stolze Lima}

Múltiplos foram os sentidos atribuídos à experiência da mestiçagem no Império do Brasil, através dos quais diferentes atores sociais procuraram apreender e elaborar a forte heterogeneidade sociocultural existente. Focalizá-los através do movimento que defendeu a existência de uma "língua brasileira" pode deixar ver um pouco daquela sociedade escravista, formada por homens e comunidades de procedências variadas, moldada pelo tráfico de africanos até 1850 , por imigraçōes e migrações ininterruptas, e que passou pelo processo de construção do Estado Nacional ao longo de boa parte do século XIX. Entre a fortíssima diversidade — social, lingüística, étnica, racial, regional - e a construção da unidade nacional, os debates sobre uma língua brasileira, inseridos no horizonte mais amplo do romantismo, podem ser analisados como um ponto estratégico de visão para os historiadores.

No século XIX, a língua foi objeto das políticas educacionais e teve papel ativo na formação dos Estados nacionais. Pode-se afirmar que este foi o momento por excelência da definição das línguas nacionais modernas, ocorrendo uma intervenção inédita do Estado nos falares da população, a ponto de criar, no homem comum, a expectativa de um padrão lingüístico uniforme que até então era próprio de grupos socioculturais restritos. ${ }^{1}$ Além disso, o olhar nacionalista sobre a língua aglutinou a ação de lexicógrafos, filólogos, gramáticos e escritores. A difusão da língua nacional impressa, como acentuou Benedict Anderson, desempenhou um papel importante - porque cotidiano, corriqueiro, indireto — na gestação

\footnotetext{
* Artigo recebido em fevereiro de 2003 e aprovado em junho de 2003. Uma versão reduzida deste trabalho foi apresentada no VII Congresso Luso-Afro-Brasileiro de Ciências Sociais, no Rio de Janeiro, em 6 de setembro 2002.
} 
do sentimento de comunidade nacional. Governar, criar a soberania sobre o território e a população, consistiu também em "difundir a língua nacional", em construir uma uniformidade da fala, em transformar "uma miscelânea de povos em uma comunidade nacional". ${ }^{2}$

Analisando a formação do Estado nacional no Brasil, Ilmar Rohloff de Mattos destaca a importância da difusão da língua nacional e sua gramática como parte das propostas e medidas relativas à instrução:

[...] não se tratava mais de apenas ensinar a 'ler, escrever e contar', como acontecera nas escolas da Colônia. Tratava-se de difundir o mais amplamente possível a 'língua nacional', sua gramática incluída, de modo a superar as limitaçôes de toda natureza impostas pelas falas regionais, e assim reproduzindo em escala mínima e individual o esforço gigantesco que, em escala ampliada, era desenvolvido pelos escritores românticos, Alencar à frente. ${ }^{3}$

Incorporar a "casa", o espaço familiar e cotidiano, ao projeto de uma unidade cultural nacional, era um caminho para reduzir as influências mais locais e particulares. Pela língua, ao máximo unificada, abriam-se caminhos para valores, imagens, representaçóes e sentimentos de nacionalidade.

No caso do Império do Brasil, certos escritores e dicionaristas falaram, porém, não apenas em língua nacional, mas na existência de uma "língua brasileira", em que se assentaria a "literatura brasileira". Sem supor que a expressão "língua brasileira" tenha um sentido evidente ou natural, encontra-se todo um esforço de definição, que pode ser inserido no quadro mais amplo das lutas em torno do sentido da noção de "brasileiro", iniciadas no processo de emancipação política, retomadas e apropriadas pelos grupos intermediários urbanos, entre outros, durante o governo regencial (1831-40) e submetidas a uma leitura de certa forma mais consensual e pacificadora pelo movimento romântico de meados do século.

Antes de mais nada, cumpria sublinhar que "língua brasileira" não seria a língua falada pelos "índios", como advertiu um pioneiro e modesto dicionarista, autor do Dicionário da Língua Brasileira, de $1832^{4}$. Preocupação ainda necessária para Joaquim Norberto de Sousa e Silva, que usou a expressão como título de um artigo publicado na revista Guanabara em 1855, que insistia em um significado diferente, evitando-se entendê-la como "língua guarani”, "língua geral do Brasil" ou "língua brasílica". 
Considerar o projeto do periódico Guanabara - Revista Mensal Artística, Cientifica e Literária pode ser um caminho para um apanhado mais largo sobre a questão, procurando transver, no debate sobre a língua, as inquietaçôes daquela sociedade, ou ao menos dos seus dirigentes, especialmente em relação àquele "povo mesclado e heterogêneo", ${ }^{6}$ àquela "nação composta de raças estranhas", 7 àquela "multiplicidade das raças". ${ }^{8}$

Como se poderia, simbolicamente, conceber estas divisões em uma unidade? A concepção de nação no Império do Brasil não operava uma união direta entre os cidadãos. Ao contrário, as diferenças eram percebidas como naturais. Mas nem por isso esta foi uma operação tranqüila ou isenta de disputas, tendo deixado vestígios a serem recuperados. Vale, portanto, interrogar sobre como a construção de uma língua nacional lidou com as diversidades étnica, lingüística, social, regional, entre muitas outras.

A difusão de um "espírito de associação" na formação do Estado Imperial constituiu uma dimensão essencial do que Ilmar Rohloff de Mattos conceitua como as ações do governo do Estado sobre o governo da Casa, atuando de modo eficaz e duradouro, na medida em que procuraria construir um consenso ${ }^{9}$ em torno da suposta unidade moral, cultural, histórica da nação. O movimento romântico teve neste processo um papel central. A literatura brasileira, a língua brasileira, a história e a ciência nacionais, ajudaram a construir aquela unidade.

Revistas literárias, acadêmicas e científicas foram órgãos importantes do romantismo brasileiro e, de forma mais ampla, da atividade intelectual naquele contexto. Tratava-se, no mesmo volume, de química, botânica, história e poesia. Notícias sobre livros publicados em diferentes locais do Império e resoluções de equações matemáticas conviviam nesses projetos, dedicados às "classes da sociedade que procuram um passatempo instrutivo". ${ }^{10}$ A revista Guanabara, ao lado da Revista do Instituto Histórico, da Revista Brasileira, entre outros títulos, representavam o que foi apontado por um contemporâneo como uma "imprensa livre", pois o Brasil possuiria então

[...] perto de 80 publicações periódicas, muitas de grandiosas proporções, e outras científicas e literárias, das quais algumas redigidas com gosto e talento; e todas enfim disseminando por toda a superfície do império mais de oito milhões de folhas proporcionadas aos gostos e instrução dos seus leitores. ${ }^{11}$ 
Com evidente intuito de frisar a diferença em relação à "anarquia" atribuída à imprensa do período regencial, especialmente no início da década de 1830, essas publicaçōes manifestariam não qualquer liberdade de expressão, mas sim uma com conteúdo preciso: uma "liberdade regrada" ${ }^{12}$, com apoio financeiro e político do Estado. O contraste entre o período regencial e a época de meados do século, aproximadamente entre as décadas de 1840 e 1860, constitui uma imagem recorrente entre os contemporâneos, sejam historiadores, publicistas, escritores etc., imagem essa que contrapõe uma turbulência, uma tormenta, uma exaltação a uma paz, estabilidade, vitória da civilização e da ordem. Tratar-se-ia, nessas décadas, do "apogeu do Segundo Reinado": as revoltas provinciais controladas, a ameaça de fragmentação territorial debelada, o Imperador coroado, a conciliação entre os partidos. Trata-se, portanto, muito mais da imagem dos próprios dirigentes imperiais sobre seu próprio tempo ${ }^{13}$ do que de uma categoria neutra de análise. Esse contexto tornava especial o princípio de unidade, que atuava muito fortemente nas elaboraçôes simbólicas sobre a nação.

A revista Guanabara mantinha estreita relação com o Imperador, que encabeçava a lista dos assinantes exposta ao final do volume. Pertencia ao mesmo círculo social e intelectual relacionado ao Instituto Histórico e Geográfico Brasileiro. ${ }^{14}$ Anunciava o tempo em que a "geração que nasceu em 1825" - ano de nascimento do monarca, chegava ao poder, como o início de uma "época orgânica", a da emergência de "uma nação na América", onde reinariam "o amor de pátria" e "as virtudes da razão social". ${ }^{15}$

A Guanabara, na tomada de posição expressa nas suas páginas iniciais, falava de uma dualidade que deveria ser sanada, de uma oposição maléfica para a nação, entre uma natureza magnifíca, e, em contraste gritante, o homem que a habita:

Tudo é grande e prodigioso neste Brasil; tudo se apresenta debaixo das formas mais belas e mais colossais, - exceto o homem! ${ }^{16}$

Oposição temática fortíssima também no texto "Meditação", escrito por Gonçalves Dias — um dos editores da revista, além de ter sido um dos mais ativos militantes de uma expressão literária nacional — em sua juventude, e que veio à luz nas páginas da mesma: 
E sobre essa terra mimosa, por baixo dessas árvores colossais, vejo milhares de homens de fisionomias discordes, de cor vária e de caracteres diferentes. ${ }^{17}$

Uma solução para as diferentes divisões poderia estar exatamente na língua. O cônego Joaquim Caetano Fernandes Pinheiro, historiador, crítico literário ${ }^{18}$ e um dos editores do periódico, sentiu-se obrigado a responder a um artigo de Francisco Nunes de Souza, ${ }^{19}$ ali publicado. As tensóes entre pensar a nação e gerir a população — prática igualmente estratégica no processo de centralização política —, entre a unidade e as divisões moveram a resposta do Cônego ao texto "Geografia Histórica, Física e Política do Brasil”, onde Nunes de Souza refez cálculos sobre a população, contestando os números apresentados por autoridades reconhecidas no tema, Haddock Lobo e Angelo Thomaz do Amaral, sobre a cidade e a província do Rio de Janeiro respectivamente. O sentido geral de sua crítica era apontar um número maior da população global e, sobretudo, para uma maior proporção de escravos. Na província do Rio de Janeiro, Nunes de Souza afirmava que haveria não 460 mil habitantes livres e 440 mil escravos (soma dos resultados apresentados pelos dois recenseadores citados acima), mas 500 mil homens livres e — para o pasmo e terror dos dirigentes imperiais - um milhão de escravos.

De fato, havia uma forte tendência da parte dos proprietários em não declarar o número exato de escravos, fugindo aos impostos devidos. ${ }^{20}$ Mas a questão do número de escravos, naquele momento, tinha implicações mais profundas que a questão fiscal. Tratava-se de administrar a formação da população, seu crescimento e distribuição ordenada pelo território. Nunes de Souza aproximava-se da opinião não exatamente abolicionista, mas contrária aos escravos e mais precisamente contrária ao tráfico internacional e ao que era visto como ameaça de uma "africanização" da nação, e que no início da década de 1850, já decretada naquele ano a Lei Eusébio de Queiroz (que determinou a repressão ao tráfico internacional de escravos), curiosamente ainda precisava se fazer ouvir ${ }^{21}$. Segundo o autor do artigo, o quadro trágico retratado pela estatística mostrava, no conjunto do país, que haveria para cada homem branco, dois "de cor". O desequilíbrio situaria o orgulhoso Império do Brasil em posição de inferioridade em rela- 
ção aos outros países da América, e o motivo seria agravado exatamente pela diversidade racial da população.

A preocupação ali expressa tinha alguns pontos em comum com as questôes levantadas por Francisco Adolfo de Varnhagen no seu "Memorial Orgânico", onde propunha, em seus próprios termos, que o Brasil deixasse de ser uma colônia para tornar-se uma nação. Além da divisão territorial, incluindo a mudança da capital para o centro geográfico do Império, dos limites espaciais detalhados, Varnhagen ali preocupava-se com a população, cujo problema para ele não era tanto o pequeno número, mas justamente a heterogeneidade. ${ }^{22} \mathrm{O}$ autor defendia a escravidão indígena, como forma de superar a ameaça da africanização. A proposta incluía ainda uma certa depuração, no ambiente urbano, da presença escrava, limitando seu número nas cidades mais populosas.

No processo de formação do Estado imperial, a estatística ocupou um lugar estratégico. Em vez de entender o Estado como um aparelho forte previamente dado, constituído de forma definitiva, pode-se distinguir um poder cujo exercício dependia deste tipo de prática e representação em torno da ordenação da população. E naquele duplo gesto de conhecer e ao mesmo tempo construir a população, a operação básica era recortar conjuntos e subconjuntos, estabelecer diferenças, principalmente diferenças de cor, de condição livre ou escrava, de nacionalidade. Deve ser significativo que na década de 1830 ocorresse a forma "Estadística" para fazer referência à atividade que seria "força e grandeza de um país", e que de fato consistiu em um instrumento e meio de um governo que passava, necessariamente, pela administração. ${ }^{23}$

No número seguinte da Guanabara, o Cônego Pinheiro escreveu "Uma Resposta” à análise estatística de Nunes de Souza, procurando afastar a idéia de que "marchamos na retaguarda das repúblicas da jovem América". Longe disso, o destino de grandeza do Brasil contrastaria com "as repúblicas da raça espanhola”. E, quanto às divisões e desequilíbrios entre livres e escravos, brancos e pretos, fazia também uma afirmação que não deixa de ser, à sua maneira, uma projeção: no Brasil encontram-se

[...] ligadas as suas diversas partes pela comunidade de interesses, de língua, de Religião. ${ }^{24}$ 
Unidade existe, segundo o Cônego, dada pelos “interesses” (que, por ser algo do plano da imaginação, o autor não explicita de forma mais direta), pela religião, que sabemos ser a oficial do Império, e pela língua. Essas são as urdiduras que fazem das "diversas partes" do Brasil uma nação. $\mathrm{O}$ caráter vago e indefinido dos "interesses" é correlato à mesma dificuldade de se definir o que era a nação. Antonio Candido comentou esta característica do nacionalismo literário: entre os contemporâneos, "ninguém saberia dizer com absoluta precisão" em que consistia a literatura nacional. ${ }^{25}$ Não se trata de apontar ali um defeito ou falta no argumento do cônego Pinheiro, mas sim algo imanente às comunidades imaginadas: tratava-se de um certo sentimento, uma determinada tradição, um comportamento singular, de fato indefiníveis. ${ }^{26}$ No caso da língua, sempre associada à religião católica - conforme pode ser percebido em outros românticos acredito que podemos encontrar uma elaboração, no plano simbólico, que associava a hierarquia, a escravidão e a desigualdade, à crença na unidade da alma humana. Gonçalves de Magalhães, em Os indígenas do Brasil perante a história, considera a hipótese de ter havido "no princípio, um só continente, uma só raça, uma só língua”. Ter-se-ia seguido uma posterior dispersão que não anulou a "unidade da espécie humana" ${ }^{27} \mathrm{Se}$, por um lado, as idéias sobre uma língua única e original são clássicas, alimentando de teorias a mitos, ${ }^{28}$ naquele contexto específico de uma sociedade escravista que passava pelo processo de formação do Estado nacional, poderiam servir como atenuante simbólico da desigualdade.

Assim como durante o período de consolidação da emancipação política (1822-31), em meados do século XIX as disputas e conciliações com Portugal estão presentes na definição da literatura e da língua brasileiras então construída. Tratava-se de proclamar uma nova Independência $;^{29}$ no entanto, outros eram os campos de batalha, e a marca já não é a do exaltado antilusitanismo. No campo de tensões constituído pela língua literária, travou-se uma relação ambígua com Portugal, pontuada por filiações e distanciamentos. Os escritores empenhados na tarefa nacional, seguindo um percurso que, às vezes, confundia-se com o dos historiadores, recorreram a uma experiência própria, a oralidade, para afirmar-nos distintos. Mas esse recurso à oralidade foi tenso e difícil, prevalecendo as seleçôes, as distinções, as depuraçõoes em relação ao que seria digno de ser elevado 
à expressão literária. Seleções no que dizia respeito às influências exercidas pelas outras línguas praticadas no território. Das indígenas, inúmeras, era eleito o tupi, como a língua dos índios. Das africanas, muito se denegou e silenciou, mas o tempo gasto com os desmentidos sempre pode ser significativo.

Joaquim Norberto de Sousa e Silva nasceu no Rio de Janeiro, em 1820, e faleceu em 1891. Como era próprio da época, aliou suas atividades intelectuais de historiador, escritor, autor de artigos diversos etc. com a carreira no funcionalismo público. Chegou a ser presidente de uma das mais influentes academias do Império, o Instituto Histórico e Geográfico Brasileiro. Recentemente, sua obra tem sido objeto de novas edições críticas e sua atuação como pioneiro nos estudos da "história da literatura brasileira” tem sido evidenciada. ${ }^{30}$ Não só no artigo do qual passaremos a tratar, mas no conjunto de sua obra em torno da literatura, atuou em defesa da língua brasileira.

Como indicado acima, o reconhecimento da literatura brasileira esteve articulado, por alguns românticos, à língua brasileira. Escritores portugueses contrários a tal reconhecimento afirmavam que a língua e não a terra definiria a literatura. Se no Brasil os escritores escreviam em português, então a literatura seria portuguesa. ${ }^{31}$

No entanto, se por um lado a vontade de diferenciação em relação à ex-metrópole levava à busca dos fatores desta identidade própria, valorizando a terra $;{ }^{32}$ por outro lado, permanentemente, a ruptura com Portugal tinha que ser equilibrada, pois foi a garantia de uma civilização. Teríamos a herança da língua e da religião: eis por que não seríamos selvagens. Os brasileiros seriam "irmãos” dos portugueses, herdeiros da língua, tendo portanto direito à mesma. Os limites da diferenciação estavam dados: "somos cristãos e falamos português".

Nas palavras de Joaquim Norberto:

[...] ao menos cá de mim para mim tenho, que quando disser língua portuguesa, entenderão por tal o idioma de que se usa na velha metrópole, e quando 
disser língua brasileira, tomarão por tal a que falamos, que é quase aquela mesma, mas com muitas mudanças. ${ }^{33}$

Apoiando-se em autoridades reconhecidas, citando autores franceses, portugueses e de outras nacionalidades que defenderam o destino da língua portuguesa no Império americano, Joaquim Norberto afirma que as mudanças viriam do clima, da mistura de raças, de vocábulos e costumes indígenas. Sabe-se que o indianismo foi um dos principais aspectos do nacionalismo literário, ${ }^{34}$ e expressou-se não só como tema de obras ficcionais e poéticas, como na própria escrita, através da introdução de vocábulos, geralmente de suposta origem tupi-guarani. Dos mais duradouros exemplos pode ser citado o romance Iracema, através do qual José de Alencar, em 1865, articulava ao significado atribuído às palavras tupi e sistematicamente ensinado nas notas de rodapé, os supostos costumes e principalmente um código moral, sempre entendidos como elementos do passado. Alguns anos antes, Gonçalves Dias publicara seu Dicionário da Lingua Tupi. ${ }^{35} \mathrm{~A}$ prática tornou-se tão comum que chegou ao exagero. Macedo Soares, futuro autor do monumental projeto de um Dicionário Brasileiro da Lingua Portuguesa, de 1888-1889, lembrava que muitas vezes tais palavras, longe de expressarem uma literatura nacional, não eram entendidas pelo "povo":

Puseram em moda o dicionário dos dialetos indígenas, e, em vez de apoderarem-se das idéias, estudaram primeiro os vocábulos que deviam exprimi-las. Nasceu daí uma poesia que o povo não entendia, nem era possível entender, tão bárbara e alheia a seus ouvidos, tão estrangeira como se fosse escrita em chinês ou sânscrito: e quando o povo não entende, a poesia não é nacional. ${ }^{36}$

Em tom irônico, como de resto é prática em todo o artigo, Joaquim Norberto referia-se àqueles que ancoravam a necessidade de se conhecer a língua guarani à zoologia, etnografia e botânica, como Francisco Adolfo de Varnhagen, ${ }^{37}$ outro historiador envolvido com a questão da língua, que admitia que o português no Brasil sofrera uma diferenciação no léxico e na prosódia, mas advogava a tradicional unidade da língua escrita. ${ }^{38}$

Nessa identidade em que cumpria também produzir o outro exterior, a relação com Portugal parecia vital. Joaquim Norberto considerou a repercussão da obra $O$ Caramuru, de Santa Rita Durão, publicada no sé- 
culo XVIII, e que parecia ocupar um ponto de referência naquele processo: pelo lado "brasileiro" seria um modelo para a literatura nacional, pelo lado dos críticos portugueses que censuravam o desrespeito aos clássicos, seria a prova do quanto o tentame chegaria ao ridículo:

Cá está o nosso Santa Rita Durão, que como tal me saberá guiar melhor que ninguém. O seu belo poema foi friamente recebido pelos portugueses. Durão o previra quando disse que eles haviam de estranhar os nomes de alguns de seus heróis, mas que os nomes dos alemães e dos ingleses não eram menos bárbaros. A isto lhe responderam os portugueses que os nomes brasileiros abundavam de vogais, que faziam parte de uma língua harmoniosa e doce, que não eram bárbaros, mas que eram RIDÍCULOS!... Ridículos, e que faziam rir; ridículos como Paraguaçu, Caeté, Imboaba e Jacarandá!

Então, justo os nomes dos "heróis" brasileiros soariam ridículos aos ouvidos portugueses, por causa do número de vogais. E ele tenta, como se diz, dar o troco, indicando palavras também ridículas nos lábios portugueses. Mostra ainda como os brasileiros, ao usar artificialmente pronúncias portuguesas (cousa e não coisa, doudo e não doido, ou "lâi", e não lei), e ao escrever de forma diferente da que fala, seriam, também ridículos.

Seu texto enfim é uma espécie de retomada do estado geral da questão, mapeando autores um pouco anteriores ou contemporâneos (Visconde de Cairu, José Bonfiácio, Pereira Coruja, Santiago Nunes Ribeiro e outros), com os quais em geral mantém uma curiosa relação que oscila entre reconhecê-los como autoridades e exigir deles tomadas de posição mais radicais. Aí reside a importância do artigo, bem como do tratamento dado pelo autor ao longo de sua obra a esse tema.

Em meados do século XIX, começaram a ser produzidos dicionários e vocabulários, dos quais desprende-se uma inclinação no sentido da abrangência da língua praticada — falada ou escrita — , e uma certa tendência à incorporação e documentação de elementos próprios ao Brasil (mesmo operando seleções inevitáveis). De forma distinta, no caso da língua brasileira pensada literariamente a seleção sobressaía, e parecia não estar em questão nenhuma tendência a uma incorporação incondicional. São as tensões entre língua literária e língua falada, a mostra de uma vontade de aproximação com o "nacional", às vezes incompreensível para o homem comum, como salientado por Macedo Soares. 
Procurando invalidar as constantes censuras e críticas portuguesas, o romantismo teve uma relação ambígua com a oralidade. De um lado, visitou-a como prova dos rumos diferenciados do português no Brasil. De outro lado, nunca tomou esta visita como devendo absorver indistintamente e em estado bruto tudo o que era encontrado. José de Alencar construiu sua argumentação sobre a autonomia da língua literária no Brasil apontando exatamente esse processo de depuração que o poeta realizaria diante do "vulgo" ${ }^{39}$ Outras vezes, admitia-se uma diferenciação da fala no léxico e na prosódia, mas preservava-se a tradicional unidade da língua escrita, como foi o caso já comentado de F. A. Varnhagen. ${ }^{40}$

A linguagem não podia deixar de ser mais um elemento de diferenciação naquela sociedade com linhas de hierarquia ao mesmo tempo claras e tensas. Um dos que lutaram, através da sua pena, contra as interpenetrações lingüísticas foi o padre Lopes Gama, de Pernambuco, que escrevia em 1842 no seu Carapuceiro:

É verdadeiramente lastimosa a linguagem ou gerigonça luso-africana de muita gente nossa, e não só do mençalho, como até de hierarquia elevada. Já não tratarei da prosódia ou acentuação da voz, pela qual estendem tudo que deve ser breve, e formam desta arte uma linguagem tão morosa que enfastia e quase dá sono. Vemos muitas vezes uma menina galante, viva e espirituosa. Mas em falando é uma miséria; e o mais é que, se alguém lhe diz que se corrija de falar tão descansada e preguiçosamente, arrebita o nariz, chofra-se e responde desdenhosa: 'Eu nasci no Brasil, e não sei falar língua de marinheiro'. ${ }^{41}$

Sem a intenção, Lopes Gama revela que a língua falada em Recife, onde escreve, incorporara essa "gerigonça africana" (observe-se que entre os exemplos encontram-se palavras que não são de origem africana, mas indígena, como a última citada abaixo). Trata-se de vários "vícios" de pronúncia ("mandá, buscá, comê, dormi”) e de vocabulário:

Que coisa mais geral entre nós do que os vocábulos bunda, caxerenguengue, quicé, e outros muitos de origem africana? 
Curioso é que mesmo reconhecendo múltiplas causas para tais "vícios”, para Lopes Gama a principal era o contato com africanos no próprio lar, o que se aprenderia com as amas e demais escravos. Ora, essa seria uma inversão sem par, os "primeiros mestres" sendo exatamente os escravos e africanos, grave exatamente porque aconteceria entre as pessoas "da classe grada da sociedade”. Sua posição refletia os valores moralistas da sociedade pernambucana, que ele acreditava ser urgente reformar, mas não revolucionar. ${ }^{42}$ Outro caso curioso, também relacionado a Pernambuco e da mesma época, é citado por Luiz Felipe de Alencastro ao comentar as tensões entre a fala da Corte - que começava a despontar como padrão — e os falares regionais e provinciais. O deputado Manuel Carneiro da Cunha foi apelidado de "deputado caçanje" (do reino de Caçanje, em Angola), por ter uma linguagem supostamente povoada de africanismos, ${ }^{43}$ portanto totalmente inapropriada para a tribuna parlamentar.

O escritor espanhol Juan Valera ${ }^{44}$ publicou, originalmente na Espanha, e traduzido nas páginas da Guanabara, o artigo "Poesia Brasileira", cuja análise permite trazer à luz uma tensão entre diferentes formas de conceber a nacionalidade. $\mathrm{O}$ autor procurava olhar para "todas as raças de que é composto" o povo brasileiro e admirava nele uma comum disposição poética e musical. Procurando responder a uma questão já levantada por Gonçalves de Magalhães, ${ }^{45}$ diz que entre os índios haveria uma disposição natural para a música e para poesia, também revelada pelos negros que enquanto trabalham, cantam "a monótona música e os rudes versos".

Ao lado da poesia brasileira, Valera reconhecia a preocupação em cunhar uma língua própria, "a que chamam nacional para não denominá-la portuguesa”, bem como o uso de palavras "tomadas nos dialetos americanos, e ainda atrevo-me a afirmar que têm adicionado também palavras das línguas africanas, v. g. da língua buda [sic] da costa do Congo, que é uma das mais perfeitas, que falam os negros".

Não deve passar despercebida a inexatidão tipográfica do termo bunda. A palavra é uma variação de bundo, "indivíduo dos bundos, indígenas bantos de Angola", expressando ainda "a língua dos bundos". Por extensão, seria também "qualquer língua de negros" ou uma "maneira incorreta de exprimir-se; linguagem estropiada; bunda” ${ }^{46} \mathrm{O}$ erro gráfico provavelmente trai, antecipando-a, as ressalvas feitas ao artigo pelos editores da 
revista, que, exatamente neste ponto, abriram uma nota de rodapé com a seguinte advertência:

Parece-nos sumamente injusto o que diz o ilustre viajante; porque se algumas palavras dos dialetos africanos se acham introduzidas entre nós, não são elas jamais empregadas por pessoas instruídas e bem educadas. ${ }^{47}$

A experiência de Juan Valera na cidade do Rio de Janeiro certamente marcou sua percepção daquilo que reconheceu como uma poesia dos negros. Diferentes línguas oriundas da África ali eram correntes, não só nos momentos de trabalho, como no exemplo citado, mas em outras oportunidades em que africanos ou descendentes estivessem reunidos. Mary Karasch, sintetizando diferentes testemunhos contemporâneos, principalmente de estrangeiros, falou das ruas da cidade como um "museu de línguas africanas. ${ }^{48}$

Segundo Valera, a língua portuguesa funcionaria como uma certa nacionalização, pois aqueles "cedo esquecem-se dos seus pátrios dialetos", passando a compor coplas "em mau português". Nesse ponto, sua posição coincide com a do cônego Pinheiro, que acreditava na língua como princípio de unidade, apesar das divisões e conflitos da escravidão. É de se notar ainda que sua afirmação sobre o uso de palavras emprestadas dos "dialetos americanos" não foi objeto de ressalvas pelos organizadores da publicação, uma vez que compunha o horizonte de expectativas, e já se consagrara como prática literária.

Havia todo um cuidado em discernir o que poderia ser alçado da oralidade para a língua literária, considerado digno - como alguns vocábulos indígenas da zoologia, botânica, topografia, dentre os quais alguns apropriados pela titulação de nobres —, e o que poderia até ser reconhecido como parte da língua falada, mas delimitado como próprio de pessoas não instruídas, mal educadas, ou que não se portavam como seria adequado à sua posição social, e, portanto, indigno de compor a escrita. Juan Valera, ao mostrar-se sensível à presença das línguas africanas no cotidiano, destoava dos intelectuais mais empenhados em forjar os retratos simbólicos da nação. 
Ao investigar as origens nacionais, os intelectuais românticos — lembrando que, àquela altura, não havia propriamente especialização das atividades que separasse, por exemplo, a literatura, das ciências ou da história - enfatizaram a língua respondendo à forma como entendiam o homem, notando-o em sua natureza moral e expressando seu espiritualismo. A língua, construtora de uma unidade, capaz de transformar bárbaros em elementos, ainda que diferenciados e circunscritos, de uma nação, permitia que nos desviássemos de uma selvageria completa, apontada pela perspectiva mais naturalista, privilegiadora das diferenças e transformações físicas, e que então começava a se esboçar. Desde o século anterior, conforme mostra por exemplo Michel de Certeau no contexto da França revolucionária, as reflexôes sobre a língua estavam empenhadas em restaurar uma unidade, encontrando raízes comuns, ou uma língua originária a ser extraída das diferentes línguas praticadas, ou ainda buscando regularidades de qualquer ordem. ${ }^{49}$

A arquitetura da língua nacional tinha um desenho curioso. Rompiase com a "escravidão" ante Portugal, mas valorizava-se a colonização lusa como o caminho que abria a nossa nação para uma língua e uma religião. Da multiplicidade de línguas indígenas, elegeu-se o tupi — transformado, elaborado, moldado pelo poeta ${ }^{50}$ — como aquela que merecia incrustrarse, através de vocábulos usados no texto literário, na expressão literária nacional. Quanto às línguas africanas, encontra-se uma tensão entre uso e denegação. Não se deve projetar sobre os contemporâneos, porém, uma perfeita distinção (que suporia não só o conhecimento mas, mais ainda, o interesse lingüístico) sobre o que seria um vocábulo banto ou, por exemplo, tupi. Atuava com muito mais força uma indisposição prévia sobre aceitar o que pudesse ser identificado com as culturas africanas. E a expressão de fato utilizada na comunicação diária — resguardando-se as diferenças entre os espaços privado e público: a casa, a família, a tribuna parlamentar, o texto literário... - era algo certamente pouco influenciado por todo esse projeto de nacionalidade lingüística, de toda essa elaboração intelectual.

Confrontar a formação da identidade nacional e as análises estatíticas, campo igualmente estratégico da centralização política do Estado Imperial, evidenciou tensões entre diferentes retratos do país, entre a concepção da nação e a composição da população. Indicou ainda como as diversidades 
atravessavam a todo tempo o caminho sobre o qual se assentaria uma unidade nacional.

Caminho que, no que toca à língua nacional, ainda tem muito a ser explorado pela historiografia. Atentar para a historicidade da unificação da língua contribui para sua desnaturalização, para os procedimentos de sua construção, passados e atuais. ${ }^{51}$ A possibilidade de análise historiográfica se fortalece na medida em que não sejam isolados os elementos, as idéias relativas à língua nacional, de outros aspectos do contexto, e, ao contrário, reconduzidos à sociedade que produziu esses sentidos. No caso específico do artigo, procuramos nos situar em um mirante, apostando em como a questão da língua consistiu numa experiência de mestiçagem, por um lado inevitavelmente marcada pela diversidade sociocultural, e por outro carregando as propostas de hierarquização e silenciamento na formação do Estado nacional.

\section{Bibliografia}

ALENCAR, José de. Pós-Escrito à segunda edição. Iracema - ediçãa do centenário. Rio de Janeiro: Institulo Nacional do Livro, 1965.

ALENCASTRO, Luiz Felipe de. Vida privada e ordem privada no Império. In: ALENCASTRO, L. F. (org.) História da vida privada no Brasil. São Paulo: Companhia das Letras, 1997.

ANDERSON, Benedict. Nação e consciência nacional. São Paulo: Ática, 1989.

AZEVEDO, Célia. Onda negra medo branco: o negro no imaginário das elites no século XIX. Rio de Janeiro: Paz e Terra, 1987.

BANDEIRA, Manuel. Noçôes de História das Literaturas. São Paulo: Companhia Editora Nacional, 1946, $3^{\text {a }}$ ed.

CANDIDO, Antônio. A educação pela noite e outros ensaios. São Paulo: Ática, 1987.

CANDIDO, Antônio. Formação da literatura brasileira (2º vol. 1836-1880). São Paulo: Martins, 1959.

CARVALHO, José Murilo de. Escravidão e razão nacional. Dados - Revista de Ciências Sociais, vol 3, n. 3, 1988.

CASTELLO, José Aderaldo. A literatura brasileira - origens e unidade. São Paulo: Edusp, 1999, vol. 1. 
CASTRO, Yeda Pessoa de. Falares africanos na Bahia (um vocabulário afro-brasileiro). Rio de Janeiro: Academia Brasileira de Letras/Topbooks, 2001.

CERTEAU, M., REVEL, J. e JULIA, D. Une politique de la langue. La Révolution Française et les patois. Paris: Gallimard, 1975.

CHALHOUB, S. Diálogos políticos em Machado de Assis. In: CHALHOUB, S. e PEREIRA, Leonardo A. M. (Orgs.). A história contada - capitulos de história social da literatura no Brasil. Rio de Janeiro: Nova Fronteira, 1998.

CUNHA, Manuela C. Política indigenista no século XIX. In: CUNHA, M. C. (org.) História dos Indios no Brasil. São Paulo: Cia. das Letras/Secretaria Municipal de Cultura/FAPESP, 1992.

DIAS, Gonçalves. Dicionário da Lingua Tupi chamada lingua geral dos indigenas do Brasil. Lipsia: Brockhaus, 1858.

GAMA, Lopes. O Carapuceiro. Organização Evaldo Cabral de Mello. São Paulo: Companhia das Letras, 1996.

Guanabara. Revista Mensal Artística, Científica e Literária. Rio de Janeiro, 18491851, 1854-1856.

GUIMARÃES, Manoel L. Salgado. Nação e Civilização nos Trópicos: o IHGB e o Projeto de uma História Nacional. Estudos Históricos, vol.1, nº 1, 1988, pp. 4-27. KARASCH, Mary. Slave Life in Rio de Janeiro, Princeton: Princeton University Press, 1987.

LEITE, Yonne e CALLOU, Dinah. Como falam os brasileiros. Rio de Janeiro: Jorge Zahar, 2002.

LIMA, Ivana Stolze. Cores, marcas e falas: sentidos da mestiçagem no Império do Brasil. Rio de Janeiro: Arquivo Nacional, 2003.

MAGALHĀES, Gonçalves de. Os indígenas do Brasil perante a história. Revista do Instituto Histórico Geográfico e Etnográfico do Brasil (RIHGB) Tomo 23, 1860. MARTINS, Francisco de Souza. O Progresso do Jornalismo no Brasil. RIHGB. Tomo 8, 1846. Kraus Reprint, 1973.

MATTOS, Ilmar Rohloff de. O Tempo Saquarema. São Paulo: Hucitec, 1990, 2a ed.

MAUSS, Marcel. Oeuvres. 3. Cohésion sociale et divisions de la sociologie. Paris: Minuit, 1969.

NASCENTES, Antenor. O idioma nacional. Rio de Janeiro: Tip. d'A Encadernadora, 1927. 
O Filantropo. Periódico Humanitário, cientifico e literário. Rio de Janeiro, 1849. PINTO, Edith Pimentel. O português do Brasil: textos críticos e teóricos, 1 - 18201920, fontes para a teoria e a história. São Paulo/Rio de Janeiro: Edusp/Livros técnicos e científicos, 1978.

. Oportuguês no Brasil: época colonial. In: PIZARRO, Ana (org.). América Latina: palavra, literatura e cultura. vol. 1. São Paulo/Campinas: Memorial/ Unicamp, 1993.

A língua escrita no Brasil. São Paulo: Ática, 1986.

PINTO, Luís Maria da Silva. Dicionário da Lingua Brasileira. Ouro Preto: Tipografia de Silva, 1832.

PROENÇA, Cavalcanti. José de Alencar na literatura brasileira. In: ALENCAR, José de. Obra Completa. Rio de Janeiro: Aguilar, 1959.

Revista Brasileira - Jornal de Ciências, Letras e Artes. Tomo 1. Rio de Janeiro, 1857. SANCHES, Edgard. A língua brasileira. São Paulo: Cia. Ed. Nacional, 1940 (Brasiliana, vol. 179).

SILVA NETO, Serafim. Introdução ao estudo da língua portuguesa no Brasil. Rio de Janeiro: MEC/INL, 1950.

SILVA, Joaquim Norberto de Sousa. História da Literatura Brasileira e outros ensaios. Organização, apresentação e notas de Roberto Acízelo de Souza. Rio de Janeiro: Fundação Biblioteca Nacional/Zé Mário Editor, 2002.

SILVA, José Bonifácio de Andrada e. Representação à Assembléia Geral Constituinte e Legislativa sobre a Escravatura. Paris: Firmin Didot, 1825.

STEINBERG, Jonathan. O historiador e a questione della lingua. In: BURKE, P. e PORTER, Roy (orgs.), História Social da Linguagem, São Paulo: Unesp/ Cambridge, 1997.

SUSSEKIND, Flora. O escritor como genealogista. In: PIZARRO, Ana (org.). América Latina: palavra, literatura e cultura. vol. 2. São Paulo/Campinas: Memorial/Unicamp, 1994.

VARNHAGEN, Francisco A. Memorial orgânico. Plano de limites e divisão do território do Brasil e situação de sua nova capital. 1849-1850. [s.l.] [s.ed.]

VILLALTA, Luis C. O que se fala e o que se lê: língua, instrução e leitura. In: SOUZA, Laura de Mello e (org.). História da vida privada no Brasil: cotidiano e vida privada na América portuguesa. São Paulo, Companhia das Letras, 1997, pp. 331385 . 


\section{Notas}

${ }^{1}$ Marcel Mauss. Oeuvres. 3. Cohésion sociale et divisions de la sociologie. Paris: Minuit, 1969, In: La nation, especialmente, pp. 596-597.

${ }^{2}$ Jonathan Steinberg. O historiador e a questione della lingua. In: Burke, P. e Porter, Roy (Orgs.), História Social da Linguagem, São Paulo: Unesp/Cambridge, 1997, p. 242.

${ }^{3}$ Ilmar Rohloff de Mattos, O Tempo Saquarema. São Paulo: Hucitec, 1990, 2a ed., p. 263.

${ }^{4} \mathrm{O}$ autor havia feito uma subscrição dois anos antes, e explicava a demora em atender aos que financiaram a publicação, pela dificuldade do projeto. Afinal "[...] cumpria consultar todos os vocabulários ao alcance, para com efeito dar o da Língua Brasileira; isto é, compreensivo das palavras, e frases entre nós geralmente adotadas, e não somente daquelas que proferiam os índios, como se presumira." Luís Maria da Silva Pinto, Dicionário da Lingua Brasileira. Ouro Preto: Tip. da Silva, 1831, Prólogo.

${ }^{5}$ Joaquim Norberto de Souza e Silva. A Língua Brasileira. Guanabara. Revista Mensal Artística, Cientifica e Literária. Tomo III, 1855, p. 100. A revista foi publicada entre 18491851 e retomada em 1854. Os diretores da primeira fase foram Joaquim de Macedo Soares, Araújo Porto-Alegre e Gonçalves Dias. Na segunda fase, este foi substituído por Joaquim Caetano Fernandes Pinheiro. Nos microfilmes da Biblioteca Nacional não constam as capas dos diferentes números da revista, que foram reunidos em dois tomos, em paginação contínua. As citações aqui feitas remetem aos tomos, não tendo sido possível recuperar, salvo quando havia indícios positivos, a data exata de publicação de um artigo.

${ }^{6}$ José Bonifácio de Andrada e Silva. Representação à Assembléia Geral Constituinte e Legislativa sobre a Escravatura. Paris: Firmin Didot, 1825, pp. 123-126.

${ }^{7}$ Leopoldo Cesar Burlamaque, citado por Célia Azevedo, Onda negra medo branco: o negro no imaginário das elites no século XIX. Rio de Janeiro: Paz e Terra, 1987, p. 43.

${ }^{8}$ A expressão faz parte do discurso de Nicolau Rodrigues dos Santos França e Leite, na fundação da Sociedade Contra o Tráfico e Promotora da Colonização, e Civilização dos Indígenas. O Filantropo, 13 de Setembro de 1850, no 76.

${ }^{9}$ Ilmar Rohloff de Mattos, op. cit., p. 157.

${ }^{10}$ Ver a nota de abertura e o índice em Guanabara, Tomo I, 1851.

${ }^{11}$ Francisco de Souza Martins. O Progresso do Jornalismo no Brasil. RIHGB. Tomo 8, 1846. Kraus Reprint, 1973.

${ }^{12}$ A expressão foi defendida na Revista Brasileira, que seria a continuação da Guanabara: "[...] a liberdade regrada, que faz hoje a nossa felicidade, e fará também no futuro a dos nossos filhos”. Revista Brasileira — Jornal de Ciências, Letras e Artes. Dirigido por Candido Batista de Oliveira. Publicação Trimensal. Tomo 1. Rio de Janeiro: Tipografia Universal de Laemmert, 1857.

${ }^{13}$ Sobre essa percepção da dimensão histórica do seu próprio tempo, ver, por exemplo, Justiniano José da Rocha em seu célebre panfleto Ação, Reação, Transação: In: Magalhães Jr., Raimundo. Três panfletários do segundo reinado. São Paulo: Cia. Editora Nacional, 1956, 
pp. 178-180. Em relação à consolidação da centralização política que marca estas décadas, Ilmar Rohloff de Mattos, op. cit., especialmente pp. 83, 116 e 128.Ver também, para a crítica a esta imagem de apogeu do Segundo Reinado nas décadas de 1850 e 1860: Sidney Chalhoub, Diálogos políticos em Machado de Assis. In: S. Chalhoub e Leonardo A. M. Pereira (orgs.). A história contada — capitulos de história social da literatura no Brasil. Rio de Janeiro: Nova Fronteira, 1998, pp. 103-104.

${ }^{14}$ Manoel L. Salgado Guimarães, Nação e Civilização nos Trópicos: o IHGB e o Projeto de uma História Nacional. Estudos Históricos, vol.1, no 1, 1988.

${ }^{15}$ Guanabara, Tomo I, 1851, p. 2.

${ }^{16}$ Guanabara, Tomo I, 1851, p. 2.

${ }^{17}$ Gonçalves Dias. Meditação. Guanabara, Tomo I, 1851, pp. 102-103. Antonio Candido, ao tratar do nacionalismo literário, menciona este texto, assinalando a posição de Dias a respeito da escravidão. Formação da literatura brasileira (2o vol. 1836-1880). São Paulo: Martins, 1959, p. 52.

${ }^{18}$ Joaquim Fernandes Pinheiro viveu entre 1825 e 1876. Foi professor de Retórica e Poética no Colégio Pedro II, e sócio do Instituto Histórico e Geográfico Brasileiro, tendo publicado obras de história dedicadas a crianças, antologias poéticas, além de volumes de história literária, como o Curso elementar de literatura nacional, de 1852.

${ }^{19}$ Francisco Nunes de Souza foi professor e publicou um manual de ensino de geografia. Morreu em 1860.

${ }^{20}$ Mary Karasch. Slave Life in Rio de Janeiro. Princeton: Princeton University Press, 1987, pp. 63-64, comenta o fracasso dos censos de 1834 e o de 1838, ambos subestimando o número de escravos.

${ }^{21}$ Em linhas gerais, esta foi a linha de atuação do periódico Filantropo, órgão da Sociedade Contra o Tráfico e Promotora da Colonização, e Civilização dos Indígenas, que arrolava os malefícios de uma africanização da nação, combatendo o tráfico internacional de escravos. A posição não é de defesa da liberdade dos escravos, mas de evitar a presença escrava no seio da "família branca". O Filantropo. Periódico Humanitário, científico e literário. 1849-1852.

${ }^{22}$ Memorial orgânico. Plano de limites e divisão do território do Brasil e situação de sua nova capital. [Por Francisco A. Varnhagen.]1849-1850. A edição original é anônima, e pode ser consultada no Instituto Histórico e Geográfico Brasileiro. Uma versão reduzida, já assinada, foi pouco mais tarde publicada nas páginas da Guanabara, tomo I, 1851.

${ }^{23}$ Bernardo Pereira de Vasconcelos, ministro das pastas do Império e da Justiça em 1837, assim se refere ao tema: "A todos, e principalmente a vós é conhecida a necessidade de uma Estadística [sic], que não só contenha um censo exato, ou pelo menos aproximado da população do Estado, como também da sua produção em geral, e particular; da sua indústria, riqueza, comércio, administração, e finalmente tudo, quanto forma a força, e a grandeza de um país. Relatório do Ministério do Império, Rio de Janeiro, Tipografia Nacional, 1838. Um dos capítulos de minha tese é dedicado à história dos censos no 
Império, especificamente à questão da classificação pela cor. Cores, marcas e falas - sentidos da mestiçagem no Império do Brasil. Rio de Janeiro: Arquivo Nacional, 2003.

${ }^{24}$ Guanabara, Tomo III, 1855, pp. 97-98.

${ }^{25}$ Antonio Candido, O Nacionalismo Literário. In: Formação da Literatura Brasileira, p. 10.

${ }^{26}$ Sobre o conceito de comunidades imaginadas, ver Benedict Anderson, Nação e consciência nacional. São Paulo: Ática, 1989.

${ }^{27}$ Gonçalves de Magalhães, Os indígenas do Brasil perante a história. Revista Trimensal do Instituto Histórico Geográfico e Etnográfico do Brasil, Tomo 23, 1860, p. 12.

${ }^{28}$ Ver, por exemplo, Michel de Certeau et al. Une politique de la langue, Paris: Gallimard, 1975, especialmente pp. 82-98.

${ }^{29}$ Antonio Candido, op. cit.

${ }^{30}$ Joaquim Norberto de Sousa Silva. História da Literatura Brasileira e outros ensaios. Organização, apresentação e notas de Roberto Acízelo de Souza. Rio de Janeiro: Fundação Biblioteca Nacional/Zé Mário Editor, 2002 (ver especialmente a apresentação do organizador do volume). Roberto Acízelo de Souza utiliza uma forma diferente do nome do autor, daquela encontrada nas fontes consultadas. $\mathrm{O}$ artigo "Língua brasileira" foi incluído na edição, tendo a mesma possibilitado uma perspectiva mais ampla do tratamento dispensado por Joaquim Norberto à questão da língua.

${ }^{31}$ Alguns escritores portugueses que militaram contra a nacionalidade literária brasileira foram Antonio Feliciano de Castilho, José de Castilho, Pinheiro Chagas e José da Gama e Castro. Ver, por exemplo, a argumentação de José da Gama e Castro, de que "a literatura não toma o nome da terra, toma o nome da língua”, citada e comentada por José Aderaldo Castello, A literatura brasileira - origens e unidade. São Paulo: Edusp, 1999, vol. 1, pp. 422-423. 32 " [...] a terra é quem dá a nacionalidade a seus filhos, e não as raças adventícias que a povoam; e dessa nacionalidade não são excluídos os que primeiros [sic] aqui nasceram antes dos filhos dos seus conquistadores”. Gonçalves de Magalhães, op. cit, p. 63.

${ }^{33}$ Guanabara, Tomo III, p. 100, grifo meu.

${ }^{34}$ Outras áreas dedicaram-se com afinco ao índio, basta consultar o índice da Revista do Instituto Histórico e Geográfico Brasileiro (que já foi também, de acordo com a época, Etnográfico e Arqueológico) para perceber a importância, talvez mais estratégica que intelectual, atribuída à questão. Nunca é demais lembrar que toda essa elaboração simbólica, literária, teórica, em relação ao "índio" pode ser relacionada à política indigenista do Estado Imperial. Manuela C. Cunha. Política indigenista no século XIX. In: Cunha, M. C. (org.) História dos Índios no Brasil. São Paulo: Cia. das Letras/Secretaria Municipal de Cultura/Fapesp, 1992.

${ }^{35}$ Gonçalves Dias. Dicionário da Língua Tupi chamada língua geral dos indígenas do Brasil. Lipsia: Brockhaus, 1858. Dias e Alencar tiveram uma participação extremamente ativa na defesa da autonomia da expressão literária no Brasil, tanto a partir do envolvimento direto nos debates intelectuais então travados, como em sua própria obra (ver Ivana Stolze 
Lima, op. cit., capítulo 3). Neste artigo, optamos por colocar o foco na produção menos conhecida, objetivando inclusive indicar o alcance da discussão.

${ }^{36}$ Antonio Joaquim Macedo Soares. "Bittencourt Sampaio”. Publicado originalmente em Flores Silvestres, $1^{\circ}$ vol., Rio de Janeiro: Garnier, 1860. Transcrito por Edith P. Pinto. O português do Brasil — textos críticos e teóricos. 1820-1920 - Fontes para a teoria e a história, São Paulo/Rio de Janeiro: Edusp/Livros técnicos e científicos, 1978. p. 43.

${ }^{37}$ Varnhagen. Florilégio da Poesia Brasileira, citado por Edgard Sanches. A língua brasileira. São Paulo: Cia. Ed. Nacional, 1940 (Brasiliana, vol. 179).

${ }^{38}$ Edith Pimentel Pinto. O português do Brasil: textos críticos e teóricos, 1 - 1820-1920, fontes para a teoria e a história. São Paulo/Rio de Janeiro: Edusp/Livros técnicos e científicos, 1978, p. xvi. Na introdução, a autora procura apresentar as reflexões sobre a natureza da língua do Brasil desenvolvidas no período. Sobre o pensamento romântico, elabora a distinção entre os "dialetistas" e os "separatistas".

${ }^{39}$ Ver por exemplo José de Alencar, Pós-Escrito à segunda edição. Iracema - edição do centenário. Rio de Janeiro: Institulo Nacional do Livro, 1965, p. 242: “[os escritores] talham e pulem o grosseiro dialeto do vulgo, como o escultor cinzela o rudo troço de mármore e dele extrai o fino lavor".

${ }^{40}$ F. A. Varnhagen. Florilégio da Poesia Brasileira, citado por Edgard Sanches. A língua brasileira. São Paulo: Cia. Ed. Nacional, 1940 (Brasiliana, vol. 179).

${ }^{41}$ Lopes Gama. O Carapuceiro. Organização Evaldo Cabral de Mello. São Paulo: Companhia das Letras, 1996, p. 421, grifo meu.

42 Sobre a trajetória de Lopes Gama e o conteúdo de sua atividade como jornalista político e social, ver a cuidadosa Introdução de Evaldo Cabral de Mello. Op. cit.

${ }^{43}$ Luiz Felipe de Alencastro, Vida privada e ordem privada no Império. In: Alencastro, L. F. (org.) História da vida privada no Brasil. São Paulo: Companhia das Letras, 1997, vol. 2, p. 35.

${ }^{44}$ Juan Valera. A poesia brasileira. Guanabara., Tomo III, 1855, pp. 197-199. Viveu entre 1824 e 1905, e foi diplomata no Rio de Janeiro. Manuel Bandeira. Noções de História das Literaturas. São Paulo: Companhia Editora Nacional, 1946, 3a ed., p. 163.

${ }^{45}$ No seu "Ensaio sobre a história da literatura no Brasil", publicado na revista Niterói em 1836 e considerado o primeiro manifesto do romantismo brasileiro, Gonçalves de Magalhães lançava as questões: "Pode o Brasil inspirar a imaginação dos Poetas? E os seus indígenas cultivaram a Poesia?”. Citado por Manuel Bandeira, op. cit., p. 338. Também sobre o interesse de Juan Valera pela defesa das literaturas nacionais, ver Antonio Candido. $A$ educação pela noite e outros ensaios. São Paulo: Ática, 1987, p. 151.

${ }^{46}$ Novo Dicionário Aurélio. Rio de Janeiro: Nova Fronteira, 1a edição, s.d, p. 233.

${ }^{47}$ Uma obra recentemente publicada procura mapear a presença das línguas africanas na Bahia: Yeda Pessoa de Castro. Falares africanos na Bahia (um vocabulário afro-brasileiro), Rio de Janeiro: Academia Brasileira de Letras/Topbooks, 2001. De acordo com o balanço historiográfico construído pela autora, os estudos sobre as línguas africanas no Brasil co- 
meçaram a ser esboçados apenas no final do século XIX, com João Ribeiro e Nina Rodrigues. Mesmo assim, as generalizações apressadas, as imprecisões seriam ainda freqüentes. Um ponto interessante despertado pela leitura deste livro é o quanto as etimologias são campos de disputa. Castro contesta, por exemplo, algumas informaçôes do dicionário $A u$ rélio, corrigindo origens atribuídas erradamente ao tupi, e que seriam, segundo ela, "bantuísmos" (ver, por ex., p. 70).

${ }^{48}$ Mary Karasch, op. cit.

${ }^{49}$ M. de Certeau, op. cit., p. 4.

${ }^{50}$ Cavalcanti Proença chama a atenção para as pesquisas etimológicas efetuadas por Alencar. Cf. Alencar na literatura brasileira. In: José de Alencar, Obra Completa. Rio de Janeiro: Aguilar, 1959. vol.1, p. 57.

${ }^{51}$ Um pequeno livro de divulgação ajuda a esclarecer as tensões que continuam a atravessar a definição de uma língua nacional: Yonne Leite e Dinah Callou. Como falam os brasileiros. Rio de Janeiro: Jorge Zahar, 2002.

\section{Resumo}

No contexto da formação do Estado Imperial no Brasil, a problemática da língua foi incorporada pelas reflexóes sobre a nacionalidade, e pode ser considerada como um dos campos produtores de sentidos em torno da mestiçagem. Especificamente, o artigo pretende discutir aspectos da polêmica sobre a "lingua brasileira" em meados do século XIX, tendo como eixo três artigos — "Uma resposta", de Fernandes Pinheiro, "A lingua brasileira", de Joaquim Norberto, e "Poesia brasileira", de Juan Valera - publicados na revista Guanabara (Rio de Janeiro, 1849-1856), e procuraremos, simultaneamente, outros indicios capazes de revelar as tensóes politicas, sociais e culturais envolvidas no processo de formação da lingua nacional.

Palavras-chave: história sociocultural; história do Brasil imperial; lingua; nacionalidade; mestiçagem.

\section{Abstract}

During the formation of the imperial state of Brazil, the issue of language tinged the discussions on nationality and representations on social and racial mixing. This essay discusses aspects of the polemic over Brazil's national language in the mid-nineteenth century, based on three articles: "A Response", by Joaquim Caetano Fernandes Pinheiro, "The Brazilian Language", by Joaquim Norberto de Sousa e Silva, and a "Brazilian Poetry", by Juan Valera, all published in the literary and scientific magazine Guanabara (Rio de Janeiro, 1849-1856). The analysis permits the uncovering of the political, 
356 - Ivana Stoltze Lima

social and cultural tensions involved in the process of the formation of a national language.

Key-words: Socio-cultural history; history of imperial Brazil; languages; nationality; racial mixing.

TOPOI, v. 4, n. 7, jul.-dez. 2003, pp. 334-356. 